\title{
The Pure Intergenerational Problem and the UNESCO Decade of Education for Sustainable Development
}

Katia Vladimirova (PhD fellow, Erasmus Mundus Joint Doctorate "Globalization, EU, Multilateralism" - Libera Università Internazionale degli Studi Sociali; Rome, Italy/Université Libre de Bruxelles, Brussels, Belgium)

"A decade into the 21st century, the world faces substantial, complex and interlinked development and lifestyle challenges and problems. The challenges arise from values that have created unsustainable societies." Bonn Declaration, 2009

\section{Introduction ${ }^{1}$}

As it is now widely agreed, climate change is a challenge that cannot be resolved within any one discipline. The complex interplay of scientific, economic, political, and social factors that characterizes the problem calls for an inter-disciplinary academic approach. This article is an attempt to connect some ideas from the field of climate ethics with the domain of education and the work of the United Nations Education, Scientific and Cultural Organization (UNESCO).

The main issue is that of a shift in values. Many scholars from various disciplines agree that resolving the climate problem as part of the global environmental crisis in general should be accompanied with a substantial shift in the values that guide our attitudes and behavior towards the environment. Environmental problems are rooted in the exploitative practices and attitudes that have dominated industrial societies for the past two centuries (Jamieson 1992). Current lifestyles in developed states are unsustainable and need to be changed. As Thomas Heberlein argues, in order to achieve behavioral change it is not enough to introduce a technical solution (called a "technical fix" in social psychology) or impose a new set of rules, like laws or taxes (a "structural fix"). Neither is it sufficient to "educate the public" in the sense of providing more information about a given problem. To change the attitudes and behavior of society it is essential to change the values that underpin this behavior, which is

${ }^{1}$ I would like to thank anonymous referees for their constructive feedback on the initial draft of this paper. 
a long and difficult process (Heberlein 2011). And if a sustainable future requires behavioral changes, then we need to focus on changing the underlying values and how to achieve these changes.

This article aims to bring together some theory-research on climate ethics, particularly the Pure Intergenerational Problem (PIP) introduced by Stephen Gardiner (2006) - and some practice-the new educational agenda proposed by the United Nations in 2002 and framed as the Decade of Education for Sustainable Development (DESD). On the one hand, it is argued in this article that PIP can be resolved (or rather, avoided) if a value shift happens that would change the very context of the problem. On the other hand, DESD is aimed at promoting the values "inherent in sustainable development" and to enable societal transformation and behavioral change. The main focus within the value shift as discussed in this article is on a particular set of values (principles, concerns) that relate present people to future generations in terms of moral responsibility. This article argues that the promotion of ethical considerations that are concerned with the distant future, and the future of humankind in general, can provide a solution to the Pure Intergenerational Problem, and it explores whether parts of this solution can already be traced within the educational agenda of the UNESCO Decade of Education for Sustainable Development.

\section{The Pure Intergenerational Problem and Future Generations}

Climate change poses a challenge to traditional moral theory, which has difficulties assigning responsibility for climate related damage to individuals and collective entities and dealing with the long-term consequences of climate change. Stephen Gardiner $(2006,2011)$ has proposed a theoretical framework to better understand how climate change creates obstacles to our ethical behavior and to explain why the world did not come to an agreement on how to resolve the problem. To explain the climate problem, Gardiner uses the perfect storm metaphor, made popular by Sebastian Junger's 1999 book recounting the real-life story of the fishing vessel Andrea Gail as it was caught up by a rare convergence of three particularly bad storms. This combination of storms was called "the perfect storm," which eventually destroyed the vessel. Using this analogy, Gardiner presents the key factors that cause problems for our ethical behavior with regard to climate change, stressing that it is the combination of spatial, intergenerational, and theoretical aspects of climate change that together converge and make us vulnerable to moral corruption. Climate change, Gardiner argues, is a "Perfect Moral Storm."

The "global storm" represents the spatial dimension of the climate problem and includes questions of distributive justice among today's rich and poor people and nations. Resolving climate change requires a balance between the interests of rich and poor states and involves developmental and historical 
responsibility issues. The "theoretical storm" is another dimension of the problem that is constituted by our current theoretical ineptitude. Gardiner argues that our moral and political theories in their current state of development are not capable of providing an informed solution to the climate problem (Gardiner 2011, 213).

Gardiner's most important contribution, however, is his analysis of the intergenerational dimension of the climate problem through game theoretical models. Global environmental problems are commonly analyzed as a Tragedy of the Commons (Hardin 1968), which is essentially a Prisoner's Dilemma involving a common resource, with states (and sometimes also corporations) as agents. In his book Gardiner applies Prisoner's Dilemma logic to generations as agents. It follows from his analysis that it is collectively rational for most generations to cooperate and restrict overall emissions to avoid climate change consequences, whereas individually for each particular generation it is rational to continue their emissions regardless of what others do. Each generation is tempted to postpone taking long-term action that would go against their shortterm business-as-usual interests, increasing the burden and the risk for subsequent generations. Gardiner calls this contradiction between collectively and individually rational choices the Pure Intergenerational Problem (PIP), which reflects the true tragedy of the climate change challenge.

PIP is relevant to a variety of intergenerational problems; however, it "is likely to be rarely (if ever) instantiated in a pure form" (Gardiner 2011, 164). Despite this, Gardiner argues, "PIP remains useful as a paradigm, since the basic structural ideas have force even under some common deviations from the idealized conditions" (Gardiner 2011, 164). For example, an application of PIP is less clear in situations in which there is generational overlap and issues of reciprocity and personal attachment are raised to challenge the relevance of PIP. However, it is far from certain that these issues automatically solve the problem, and according to Gardiner's analysis they do not undermine it completely, leaving the basic structure intact. ${ }^{2}$

Even though the application of PIP is not limited exclusively to the case of climate change, some characteristics of this particular environmental problem complicate the picture. Climate change is a resilient, seriously backloaded, and substantially deferred phenomenon (Gardiner 2006, 91). These characteristics arise from the nature of the greenhouse effect and bring about serious implications for the structure of PIP. First, the results of present emissions will not appear in the form of climate catastrophes for at least several decades (IPCC 2007, 45). That means that the present generation can be tempted to do business as usual and pass the burden of combating the problem to future generations (what Gardiner calls "buck-passing"). The

2 For a thorough analysis of the overlapping generations issue, please see Gardiner 2011, 167-74. 
problem is, though, that the damage inflicted on future people might become unfixable after passing a certain threshold, and no economic growth or wealth might be enough to resolve the problem at that stage-or at least not as effectively as it could be by the present generation.

Secondly, there is an important issue concerning the temporal fragmentation of agency. It is already extremely difficult for our moral theories to assign responsibility for climate change related damage (at individual or collective levels) within the present generation due to the spatial fragmentation of agency (e.g., emissions from driving a car in the U.S. are absorbed in the atmosphere and could contribute to draught in Africa or floods in Asia).

The situation with temporarily dispersed agents is even more complicated. In the intergenerational aspect of the problem it is not difficult to identify the cause of past emissions: prior generations (before 1992) in developed states are (unknowingly) responsible for the most of the accumulated GHG emissions due to industrial production processes. The responsibility can be assigned in this manner to previous generations, but it is impossible to retroactively enforce any sanctions or change. It is left to our and future generations to make efforts to avoid possible negative consequences of the created climate problem.

In defining our responsibility for future generations, it is useful to look back at the Earth Charter that calls for universal responsibility in terms of "identifying ourselves with the whole Earth community and our local communities," which implies that "everyone shares the responsibility for the present and future well-being of the human family and the larger human world" (Earth Charter, 1). Defining our responsibility in practical terms (reducing emissions, developing new sources of energy, protecting wild nature, etc.) would inevitably bring us to the issue of scientific uncertainty and to some difficult trade-offs between present and future well-being. "Care for future generations" can help resolve those trade-offs in a way that would allow us to avoid biases towards present people's interests that create and obstruct resolving climate change. Defining our responsibility for past and present emissions to future generations is one of the key challenges that constitute the theoretical storm.

The standard solution for situations like the Tragedy of the Commons would be an agreement that allows parties (agents) to benefit from a broader context of cooperation on trade or security issues. However, in the case of climate change (viewed as PIP) and the temporal fragmentation of agency, it is impossible to come to an agreement among generations following this logic because the agents (generations) do not coexist in time. There is no institutional platform where the "parties" could meet and negotiate and there is no institution that can guarantee compliance through centuries. Standard institutional solutions do not work for PIP, and it is not clear that the problem has any solution at all. 
If there is no institutional solution, we might explore other options: instead of changing the game structure or outcomes, we could try to change its very context to avoid playing the game in first place. Changing the context means changing the way people think about the problem and how they perceive their interests and pay-offs, which implies a shift in the values that determine our choices. PIP, as any other game with a structure similar to the Prisoner's Dilemma, emerges in a rational choice context and unearths the contradiction within rational thinking itself (i.e., the dilemma of individual rational choice going against collective rational choice that in the end leaves everyone worse off). In the case of PIP, put simply, those of us alive today tend to think that our interests (e.g., wealth and growth) are more important to us at the moment than are those of vague future generations (which we also care about, though far less than our current well-being). This happens because psychologically we value our own interests and those of our family and others close to us more than those of distant future people we don't know and will never know. In this situation we tend to choose in favor of short-term benefits that accrue to our contemporaries, thereby increasing the risks for future people.

However, when faced with this choice in the context of climate change, it is necessary that at least one generation stops "passing the buck" before it's too late: people should choose to sacrifice some of their short-term interests in favor of the future of humankind. The balance of people's incentives should be shifted from the self-interested "what's good for $m e$ " (my family and close friends, my community and contemporaries) towards the "what's good for the future of human kind" As Gardiner notes, "we will want to allow for altruistic and other motives if the PIP is to have a practical solution" (168), and care for the future of humanity is precisely the kind of "altruistic or other" motive that needs to be developed to help us resolve the problem. The solution does not require the balance to shift completely (it is unrealistic to expect people to start caring for the future more than for the present), however, it urges us to shift strongly in favor of future generations. The way this value is currently embedded in our value system is not sufficient to provide a strong motivation for collective action in the case of climate change. Concern and care for the distant future is not currently a prevailing value that underlies our choices.

The values that relate us to future generations are not explicit in political decision making. According to the UNESCO Report "Universalism and Ethical Values for the Environment" (2010), the main values that are reflected in key environmental treaties ${ }^{3}$ are human rights, sustainability, equity, common

3 These include the Universal Declaration of Human Rights (UDHR), the Convention Concerning the Protection of the World Cultural and Natural Heritage (WHC), the United Nation's Framework Convention on Climate Change (UNFCCC), The Kyoto Protocol, The Earth Charter, The Rio Declaration on Environment and Development, the 
but differentiated responsibilities, precaution, participation, vulnerability, state sovereignty, peace, and solidarity. Responsibility and care for future people are not mentioned among them. ${ }^{4}$ As Gardiner argues, the formula for future generations most frequently used in environmental politics refers mostly in practice to one or two subsequent generations (the children and grandchildren of present people). This fact has the most unfortunate implications for climate change: the problem whose cause is shaped by present people and whose impact would fall on future people cannot be dealt with when future generations are taken to include only one's children and grandchildren.

Therefore, it is necessary to develop a new way of thinking-a new value system. And a special place in this new system should be given to the ethical value that explains our moral relation to future people. In order to resolve the Pure Intergenerational Problem, it is essential to define our longterm responsibility to future generations in a way that projects over an indefinite time period, and to develop a conscious awareness for the future of humankind as part of intergenerational justice. (For the purpose of this paper, I shall refer to these ethical values as "care for future generations.").

\section{The Decade of Education for Sustainable Development and Future Generations}

A recognized way of promoting new values is education. The most prominent international institution able to advance new educational agendas globally is the United Nations Education, Scientific and Cultural Organization (UNESCO). In December 2002, the United Nations General Assembly proclaimed the UN Decade of Education for Sustainable Development, 2005-2014, (DESD), "emphasizing that education is an indispensable element for achieving

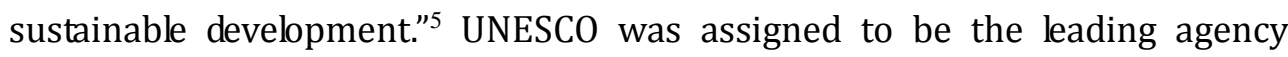
implementing activities during the DESD. According to UNESCO:

The overall goal of the DESD is to integrate the values inherent in sustainable development into all aspects of learning to encourage changes in behaviour that allow for a more sustainable and just society for all (Implementation Scheme 2005, Executive Summary).

Convention on Biological Diversity (CBD), and the Universal Declaration on Bioethics and Human Rights (UDBHR).

${ }^{4}$ However, responsibility and care for future generations might be embedded in the "sustainability" value: following the definition used by UNESCO, sustainable development "seeks to meet the needs of the present without compromising those of future generations" (UN 1987).

5 I will leave aside discussions of the weaknesses of the concepts of sustainable development and sustainability (see Schlottman 2012 or Mula \& Tilbury 2009 for more literature), and of ways other than education to promote new values, such as legal norms. 
Education for Sustainable Development (ESD) is based on values of justice, equity, tolerance, sufficiency and responsibility. It promotes gender equality, social cohesion and poverty reduction and emphasises care, integrity and honesty, as articulated in the Earth Charter. ESD is underpinned by principles that support sustainable living, democracy and human well-being (Bonn Declaration, 2009).

ESD is fundamentally about values, with respect at the centre: respect for others, including those of present and future generations, for difference and diversity, for the environment, for the resources of the planet we inhabit (Education and the Search for a Sustainable Future, 2009, 1).

It is clear that the goals set by DESD are far reaching and are aimed at altering the future more than the present. Some scholars question whether it is possible to assess the progress or results of DESD, since one decade could be too short to implement the full scope of ideas proposed by UNESCO (Pigozzi 2010, 267). Indeed, the first ten years are now considered as a starting point in which the initial national structures are set up and the ESD agenda is researched, formulated, and presented. Therefore, many assessment indicators are focused on more practical aspects of implementation, such as the "integration of educational components into plans for sustainable development" or "growing cooperation and mutual reinforcement among ESD initiatives" (Implementation Scheme 2005,43$)$, rather than on measuring the spread of new values and principles. The latter is, in any case, very hard to measure, particularly at the early stages of implementation.

Academic views on DESD range from a skepticism that views the Decade as part of a fashionable discourse of sustainable development which hides behind a neo-liberal economic and political agenda (Sauvé \& Berryman 2005, Jickling 2006) to supportive interpretations of DESD as a long-awaited opportunity for ESD (Mula \& Tilbury 2009; Calder 2005; Pigozzi 2010). These polarized opinions are rooted in the way scholars view sustainable development and sustainability. The amount of trade-offs and conflicts between sustainability and development, for example, has led some scholars to suggest that sustainable development is an oxymoron, as it is impossible to sustain more growth (Revkin 2006).

An important suggestion here comes from Christopher Schlottmann, who notes that the ESD and DESD frameworks do not reflect sufficiently inevitable trade-offs and conflicting values that students of ESD might face in the future. "If any institutionalized response to environmental degradation and economic underdevelopment is to succeed, it must address the inevitable conflicting values, conflicts and compromises that will arise" (Schlottmann 2012, 112). Schlottmann identifies at least two intersections where the conflict is very likely: conflicting values in education (between educational and larger societal aims - for example, between liberal learning and vocational training), 
and conflicting values and the environment (trade-offs between sustainability and development). These conflicts are enhanced by the urgency of the climate problem and require ESD to provide certain guidance to "help in understanding, assessing, and ... overcoming these conflicts and trade-offs" (Schlottmann 2012, 115). Therefore, Schlottmann argues further, the aims of the Decade should focus more on the development of agency, decision-making skills, and ethical empowerment. I will elaborate on the issue of trade-offs below, when analyzing the ESD value structure.

There are three main documents within the DESD framework published by UNESCO at the time of writing this piece that are important for this analysis. The main reference source about DESD is the Implementation Scheme published by UNESCO in 2005, at the very beginning of the Decade. This document contains key definitions, explanations, and background information about ESD. UNESCO also produced two important reports during DESD, in 2009 and 2012, with the third coming out in 2014. The first report, "Review of Contexts and Structures for Education for Sustainable Development" presents a "succinct yet insightful overview" of the various regional and national contexts for developing ESD (2009). The second published report, "Shaping the Education of Tomorrow: Report on the UN Decade of Education for Sustainable Development" (2012), focuses specifically on processes and learning in the context of ESD, looking at new emerging learning processes and changes since the early years of the Decade. Both reports focus on practical aspects of DESD implementation and are aimed to assess the progress being made. However, these two documents are still important for the analysis as they indicate the direction that the process has taken and allow us to compare it with the original idea outlined in the Implementation Scheme.

The Implementation Scheme contains many references to the future and future generations. "There can be few more pressing and critical goals for the future of humankind than to ensure steady improvement in the quality of life for this and future generations in a way that respects our common heritage - the planet on which we live" (8). In a way, the references to "the future of humankind" and "heritage" resemble the language used in another UNESCO document, the Convention Concerning the Protection of the World Cultural and Natural Heritage (WHC), which exhibits the strongest focus on future generations among all the treaties related to environmental protection (Universalism and Ethical Values for the Environment, 2010). In the Implementation Scheme, a document of 53 pages, "future generations" was referenced 10 times; "future," in various combinations other than "future generations," such as "sustainable future," "alternative futures," and "futuresoriented," was used 20 times. Basically, references to the future were made in every other page of the document. In comparison, the 25 page UNFCCC document contains only 3 references to the future, and all of these to "future generations." The Kyoto Protocol, a document of 21 pages, has no references to 
the future. Clearly, the language of DESD confirms the high priority given to future generations within the framework.

There are four key underlying values that education for sustainable development must promote:

- Respect for the dignity and human rights of all people throughout the world and a commitment to social and economic justice for all;

- Respect for the human rights of future generations and a commitment to intergenerational responsibility;

- Respect and care for the greater community of life in all its diversity, which involves the protection and restoration of the Earth's ecosystems;

- Respect for cultural diversity and a commitment to build locally and globally a culture of tolerance, non-violence and peace (Implementation Scheme $2005,16)$.

It is significant that concerns about future generations made their way to become the second most important value to be promoted through ESD. This concern is introduced through the lens of a human rights approach, which is strongly supported by some environmental philosophers (Caney 2010). The call for intergenerational responsibility is probably the most straightforward response to the Pure Intergenerational Problem, outlined earlier. Embedding this value and concerns for future generations into the way present people think could alter the very context in which we find ourselves, changing the incentives that determine people's behavior in a way that could help us to avoid falling into PIP. If we care for the distant future and feel responsible for the future of humankind to the extent that could be comparable to the care we have for our own children and grandchildren, and we know that our present actions threaten their very existence, we presumably would be more inclined than we currently are to stop engaging in dangerous activities in order to prevent future disasters.

Strengthening the "care for future generations" value is not a magic bullet that would completely settle conflicts and trade-offs that inevitably arise as part of any possible solution to climate change; however, it would be useful to shift the balance away from resolving those trade-offs entirely in favor of present people. But although this might create a better moral ground for resolving some intergenerational problems that reach far into the future, such as climate change, it might be less useful in other cases. For example, there might be little need to think about the future of humankind as such when trying to resolve a debt problem that would affect only those a couple of generations to come; it might be enough in such a case to think in terms of two forthcoming generations to raise concern to the appropriate level to solve the issue. In the case of environmental degradation, and particularly climate change, two generations is not enough because, as already mentioned, the negative consequences of present people's choices would fall on distant future people who in our current system of values have much lower priority for us than do 
our children, grandchildren, or the present poor and disadvantaged. I support Schlottmann's view that ESD students need to learn about possible and inevitable trade-offs related to sustainable development to be prepared to face them in the future. And when trying to resolve these trade-offs, PIP could be very useful for ESD students as a paradigm to build a stronger case for why we should care for future generations.

However, there is still the question of time frame. It is not clear from the document how far into the future the concept of future generations can reach. How many future generations can we be reasonably expected to care about? On the one hand, there are references made to the "future of humankind." With climate change posing threats to the very survival of the human race, these references are understandable. Taking responsibility for the past and acting, even against our own short-term interests, is the right thing for present people to do and is justified on the ground of the moral motivation that we are responsible for the future of humankind and that we must respect the rights of future people and not compromise their needs in favor of our own.

Yet, the interpretation of "future generations" does matter. As noted by Gardiner, often political claims that something should be done "for future generations" are in fact referring to only one or two subsequent generations: children and grandchildren. Quoting the Implementation Scheme, he adds: "as people we seek positive change for ourselves, our children and grandchildren; we must do it in ways that respect the right of all to do so ... to do this we must learn constantly - about ourselves, our potential, our limitations, our relationships, our society, our environment, our world" (8). This is the only reference made in the document to the time frame to which "future generations" applies. Considering the predicted timing of at least 100 years for the consequences of climate change (IPCC 2007, 45), promoting care for the two subsequent generations would not make much difference since our children and grandchildren would hardly be affected by the climate catastrophes of the future. On the contrary, following this logic would make it more sensible for present people to develop and employ a business-as-usual approach to accumulate more economic wealth to pass to their children.

This means that the concept of "future generations" as part of the value of "respect for the human rights of future generations and a commitment to intergenerational responsibility" needs to be elaborated and analyzed more thoroughly to give a clear message about how long into the future we should look. Resolving PIP is only possible if we can incorporate very long-term concerns into our thinking, more similar to the "future of humankind" than the "future of our children and grandchildren." Herein lies the novelty and the main difficulty of promoting this value: concern for the future of humankind has existed at least since the invention of nuclear weapons of mass destruction that are able to put an end to the human race. However, there was not much that the general public could do about this, except for civil protests. It is only now 
that concerns for the very distant future are brought directly to each individual, as it is often individual lifestyles and behaviors that lie at the very heart of climate change. Individual change, in attitudes and behavior, is crucial to overcoming the crisis, and it cannot be achieved without a deeper change and realization that the future of humankind, not just of our children and grandchildren, depends on our choices today.

\section{Conclusion}

Climate change as part of the global environmental crisis requires an interdisciplinary approach. New research developments should be informed of the progress in other disciplines in order to stay on the right track to resolve climate change through common effort. Therefore, this article is a contribution aimed to inform the fields of environmental, climate, and intergenerational ethics about the developments that are happening in the field of education in terms of promoting concerns for remote posterity. But it is also aimed to inform the field of education about philosophical views on the importance of the intergenerational aspect of climate change and the global environmental crisis, and the role of future-oriented ethical considerations in resolving it. As an interdisciplinary paper, this article attempts to address both the question of why we need to care for future generations and the question of how ethical considerations about future generations can be promoted.

It was argued that a shift in values, particularly the incorporation of ethical concerns about future generations into our thinking, can be a solution to the Pure Intergenerational Problem in a way that a new set of incentives can change the context and help us avoid falling into PIP. I then explored how these concerns are presented in the new ambitious educational agenda proposed by UNESCO in the Decade of Education for Sustainable Development. The analysis of the Implementation Scheme, the main source of reference about DESD, and which also provides key definitions and background information, shows that the document is highly oriented towards the future and incorporates concerns for future generations. It is criticized for its vague use of the term "future generations," which does not reflect the time period that the concept is to reach into the future, which is crucial with regards to our ethical behavior. It is concluded that this gap can be filled in better if informed by research on the intergenerational aspects of environmental and climate ethics.

\section{Literature}

Calder, W. 2005. "The UN Decade of Education for Sustainable Development—A Progress Report". Association of University Leaders for a Sustainable Future 7 (2): 1-8. 
Caney, S. 2010. "Climate Change, Human Rights, and Moral Thresholds". In Gardiner, S., Caney, S., Jamieson, D. \& Shue H. (Eds.), Climate Ethics: Essential Readings. New York: Oxford University Press: 163-177.

Gardiner, S. 2006. "A Perfect Moral Storm: Climate Change, Intergenerational Ethics, and the Problem of Moral Corruption". Gardiner, S. et. al. (Eds.), Climate Ethics: Essential Readings. New York: Oxford University Press: 87-98.

—. 2011. A Perfect Moral Storm: The Ethical Tragedy of Climate Change. Oxford: Oxford University Press.

Gardiner, S., Caney, S., Jamieson, D., \& Shue, H. (Eds.) 2011. Climate Ethics: Essential readings. Oxford: Oxford University Press.

Hardin, G. 1968. "Tragedy of the Commons". Science 162: 1234-1248.

Heberlein, T. A. 2011. Navigating Environmental Attitudes. Oxford: Oxford University Press.

IPCC (Intergovernmental Panel on Climate Change). 2007. The AR4 Synthesis report. Cambridge, U.K.: Cambridge University Press. Retrieved from: www.ipcc.ch.

Jamieson, D. 1992. "Ethics, Public Policy and Global Warming". Science, Technology and Human values 17: 139-153.

Jickling, B. 2006. "The Decade of Education for Sustainable Development: A Useful Platform? Or an Annoying Distraction? A Canadian Perspective". Australian Journal of Environmental Education 22 (1): 99-104.

Junger, S. 1999. A Perfect Storm: A True Story of Men Against the Sea. New York, NY: Harper

Kyoto Protocol to the United Nations Framework Convention on Climate Change. 1998. Retrieved from:

http://unfccc.int/kyoto_protocol/items/2830.php

Mulà, I. \& Tilbury, D. 2009. "A United Nations Decade of Education for Sustainable Development (2005-14): What Difference will it Make?". Journal of Education for Sustainable Development 3: 87.

Pigozzi, M. J. 2010. "Implementing the UN Decade of Education for Sustainable Development (DESD): achievements, open questions and strategies for the way forward". International Review Education 56: 255-269.

Sauvé, L., \& Berryman. T. 2005. "Challenging a "Closing Circle": Alternative Research Agendas for the ESD Decade". Applied Environmental Education and Communication 4: 229-32.

Schlottmann, C. 2008. "Educational ethics and the DESD: Considering tradeoffs". Theory and Research in Education 6: 207.

—. 2012. Conceptual Challenges for Environmental Education. Peter Lang Publishing, New York.

UNESCO. 2005. Decade of Education for Sustainable Development: Implementation Scheme. Retrieved from: http://unesdoc.unesco.org/images/0014/001486/148654e.pdf 
- 2009. Review of Contexts and Structures for Education for Sustainable Development. Retrieved from:

http://unesdoc.unesco.org/images/0018/001849/184944e.pdf

—. 2009. "Education and the search for a sustainable future". Policy dialogue: ESD and development policy. 1 Publ, illus.; ED.2009/WS/7.

-. 2010. Universalism and Ethical Values for the Environment. Retrieved from: http://unesdoc.unesco.org/images/0018/001886/188607e.pdf

—. 2012. Shaping the Education of Tomorrow: Report on the UN Decade of Education for Sustainable Development. Retrieved from: http://unesdoc.unesco.org/images/0021/002166/216606e.pdf

United Nations Framework Convention on Climate Change. 1992.

FCCC/INFORMAL/84. Retrieved from:

http://unfccc.int/resource/docs/convkp/conveng.pdf 
Katia Vladimirova

\title{
Climate Change and Future Generations: The Pure Intergenerational Problem and the UNESCO Decade of Education for Sustainable Development
}

\begin{abstract}
This article aims to bring together some theory - research on climate ethics, particularly the Pure Intergenerational Problem (PIP) introduced by Stephen Gardiner - and some practice - the new educational agenda proposed by the United Nations in 2002 and framed as the Decade of Education for Sustainable Development (DESD). PIP can be resolved (or rather, avoided) if a shift in values happens that would change the very context of the problem. On the other hand, DESD is aimed at promoting the values "inherent in sustainable development" and at enabling societal transformation and behavioral change. The main focus within the value shift in this article is on a particular set of values (principles, concerns) that relate present people to future generations in terms of moral responsibility. It is argued that the promotion of ethical considerations that are concerned with the distant future, and the future of humankind in general, can be a solution to the Pure Intergenerational Problem. The article also explores whether parts of this solution can already be found within the educational agenda of DESD.
\end{abstract}

Key words: Future generations, pure intergenerational problem, education for sustainable development

Ethics in Progress (ISSN 2084-9257). Vol. 5 (2014). No. 1. pp. 66-79.

doi:10.14746/eip.2014.1.4 